\title{
Antileishmanial, Toxicity, and Phytochemical Evaluation of Medicinal Plants Collected from Pakistan
}

\author{
Naseer Ali Shah, ${ }^{1}$ Muhammad Rashid Khan, ${ }^{1}$ and Akhtar Nadhman ${ }^{2}$ \\ ${ }^{1}$ Department of Biochemistry, Faculty of Biological Sciences, Quaid-i-Azam University, Islamabad 45320, Pakistan \\ ${ }^{2}$ Department of Biotechnology, Faculty of Biological Sciences, Quaid-i-Azam University, Islamabad 45320, Pakistan
}

Correspondence should be addressed to Muhammad Rashid Khan; mrkhanqau@yahoo.com

Received 28 February 2014; Accepted 6 May 2014; Published 19 May 2014

Academic Editor: José Domingos Fontana

Copyright (C) 2014 Naseer Ali Shah et al. This is an open access article distributed under the Creative Commons Attribution License, which permits unrestricted use, distribution, and reproduction in any medium, provided the original work is properly cited.

Leishmaniasis is an important parasitic problem and is in focus for development of new drugs all over the world. Objective of the present study was to evaluate phytochemical, toxicity, and antileishmanial potential of Jurinea dolomiaea, Asparagus gracilis, Sida cordata, and Stellaria media collected from different areas of Pakistan. Dry powder of plants was extracted with crude methanol and fractionated with $n$-hexane, chloroform, ethyl acetate, $n$-butanol, and water solvents in escalating polarity order. Qualitative phytochemical analysis of different class of compounds, that is, alkaloids, saponins, terpenoids, anthraquinones, cardiac glycosides, coumarins, phlobatannins, flavonoids, phenolics, and tannins, was tested. Its appearance was observed varying with polarity of solvent used for fractionation. Antileishmanial activity was performed against Leishmania tropica KWH23 promastigote. Potent antileishmanial activity was observed for $J$. dolomiaea methanol extract $\left(\mathrm{IC}_{50}=10.9 \pm 1.1 \mu \mathrm{g} / \mathrm{mL}\right)$ in comparison to other plant extracts. However, J. dolomiaea "ethyl acetate fraction" was more active $\left(\mathrm{IC}_{50}=5.3 \pm 0.2 \mu \mathrm{g} / \mathrm{mL}\right)$ against Leishmania tropica KWH23 among all plant fractions as well as standard Glucantime drug $(6.0 \pm 0.1 \mu \mathrm{g} / \mathrm{mL})$. All the plants extract and its derived fraction exhibited toxicity in safety range $\left(\mathrm{LC}_{50}>100\right)$ in brine shrimp toxicity evaluation assay.

\section{Introduction}

Leishmaniasis is an important protozoal disease caused by parasite belonging to genus Leishmania. Sand fly is the responsible vector for its transmission. Leishmaniasis is a major health risk and a danger to 350 million populations throughout the world. Approximately, 12 million peoples are currently infected and every year around 1-2 million new cases are appearing [1]. This disease may vary in its presentation; it can be self-healing or fatal. Various infectious types of leishmaniasis can be categorized as (a) cutaneous leishmaniasis; (b) mucocutaneous leishmaniasis; and (c) visceral leishmaniasis. Hereby, about 0.5 and 1.5 million cases of visceral and cutaneous leishmaniasis are reported, respectively. In Pakistan, leishmaniasis was first accounted in northern areas in 1960. In the beginning, it was confined to northern sphere but now it is widely spreading throughout the country [2].

All body parts especially the exposed ones are mainly targeted by cutaneous leishmaniasis. The nascent lesion may give rise to an ulcer. Systemic leishmaniasis affects internal organs of a body, that is, spleen and liver, rare in Pakistan but can prove to be fatal. The multiple ulcers resulting from multiple bites of sand fly are not a rare case in Pakistan. On the other hand, it is rapidly spreading out creating an alarming situation. Cutaneous and visceral leishmaniasis is the major threats to Pakistan, despite of mucocutaneous leishmaniasis which is rarely reported [3].

The treatments currently in use as prime therapy include meglumine antimoniate (Glucantime) in addition to pentavalent antimonials sodium stibogluconate (Pentostam) but they are harmful to some extent, require prolong parenteral administration courses, and have virulent side effects $[4,5]$. In some cases, pentamidine as well as amphotericin B are used as second line treatment which may also have lethal affects [6-8]. There is a need to develop novel drugs to counter leishmaniasis due to the existence of various hazards which include high cost of current medicines $[9,10]$ along with their possible toxic effects [11] and resistance development in parasites [12]. Because of these problems, scientists 
TABLE 1: Plant synonym, family, part, local name, and collection area of plants under study.

\begin{tabular}{lccccc}
\hline Plant & Synonym & Family & Part & Local Name & Collection Area \\
\hline A. gracilis & Asparagus capitatus subsp. gracilis & Asparagaceae & Aerial & Sha gandal & Islamabad \\
S. media & Alsine media $L$ & Caryophyllaceae & Whole plant & Gander & Islamabad \\
S. cordata & Sida veronicaefolia & Malvaceae & Whole plant & Simak & Islamabad \\
J. dolomiaea & Jurinea macrocephala Royle & Asteraceae & Roots & Nazar zela & Kohistan (KPK) \\
\hline
\end{tabular}

are in continuous search to find new drugs against these infections. Naturally existing medicinal herbs and plants are considered to be the rich supply of a variety of useful organic substances. As natural compounds are considered good and affluent source of bioactive compounds having antileishmanial ability $[13,14]$, there is a need for the identification and analysis of various natural products originated from different medicinal plants so that new drugs can be synthesized [15].

From the very beginning, plants having medicinal abilities are being used as a source of treatment against various diseases. According to an estimate, more than 25\% of recommended drugs were attained from plants with or without supplementary adjustments [16, 17]. Extensive studies have been done on the agents with antileishmanial characteristics. The extracts or bioactive substances derived from medicinal herbs are possibly the valuable and satisfying source of new therapeutic entities against parasites $[14,18]$. A wide variety of such plant species have been computed which enclose potentially effective leishmanicidal compounds [13].

In this study, four important medicinal plants, that is, Jurinea dolomiaea Boiss, Asparagus gracilis Royle, Sida cordata (Burm.f.), and Stellaria media (L.), were studied following random plant selection approach of screening.

Plants undertaken in this study are never reported in the literature for the study of antileishmanial activity. So this study was designed to explore its phytochemicals, potential in the treatment of leishmaniasis, and investigate its safety by performing brine shrimp toxicity assay.

\section{Material and Methods}

2.1. Plant Collection. Plants collections were made from the areas shown in 2011. The plants were recognized by their local names and then confirmed by Dr. Mir Ajab Khan, Department of Plant Sciences, Quaid-i-Azam University, Islamabad, and Dr. Zafar, Curator, Herbarium, Quaid-i-Azam University, Islamabad. Voucher specimens with accession nos. 24561 $(A$. gracilis), 27813 (S. media), 27824 (S. cordata), and 27823 (J. dolomiaea) were deposited at the Herbarium, Quaid-i-Azam University, Islamabad.Table 1 displays synonym, family, part of the plant, local name, and collection area.

2.2. Extract Preparation. After collection, plant samples were shade dried till the complete removal of moisture and samples were made to mesh sized powder by using plant grinder. Powders $(5 \mathrm{~kg})$ of each sample were soaked in crude methanol $(10 \mathrm{~L})$ for extraction for $72 \mathrm{~h}$. All the samples were processed two times repeating above procedure. For the purpose of filtration, Whatman No. 1 filter was used and methanol was evaporated on a rotary evaporator at $40^{\circ} \mathrm{C}$ under reduced pressure.

2.3. Fractionation. To sort the compounds in the crude extract with increasing polarity, crude extract $(6 \mathrm{~g})$ was suspended in distilled water $(250 \mathrm{~mL})$ and passed to liquidliquid partition by using solvents in order of $n$-hexane, chloroform, ethyl acetate, and $n$-butanol. The residue left behind after $n$-butanol fraction was termed as aqueous fraction (Figure 1). Rotary evaporator was used to concentrate the fraction by evaporating the solvent under reduced pressure at $40^{\circ} \mathrm{C}$. Fractions were further dried under dark and weighed and stored at $4^{\circ} \mathrm{C}$ for phytochemical and pharmacological evaluation.

2.4. Phytochemical Analysis. Qualitative phytochemical investigation of extracts and fractions for the existence of alkaloids, saponins, terpenoids [19], anthraquinones, cardiac glycosides, coumarins, phlobatannins [20], flavonoids, phenolics, and tannins [21] was performed.

2.5. Antileishmanial Activity. Stock solution for antileishmanial assay was prepared by dissolving $5 \mathrm{mg} / \mathrm{mL}$ of each plant extract and derived fractions in $1 \mathrm{~mL}$ of DMSO (dimethyl sulfoxide). Stock solutions were further diluted serially (2500, $1250,625,312.5,156.3,78.1,39.1$, and $19.5 \mu \mathrm{g} / \mathrm{mL}$ ) using DMSO to obtain the concentration from 333.3 to $1.3 \mu \mathrm{g} / \mathrm{mL}$ in the wells. Samples were filtered by using a $0.45 \mu \mathrm{m}$ syringe filter. Leishmania tropica KWH23 was previously isolated from a patient in Peshawar, Pakistan, and was characterized (data not shown). The promastigotes form of the Leishmania were grown in M199 medium with $10 \%$ fetal calf serum (FCS), HEPES buffer, streptomycin, and penicillin. Log phase promastigotes at $1 \times 10^{6} / 100 \mu \mathrm{L}$ were used for the entire assay. About $90 \mu \mathrm{L}$ of 199 media, $50 \mu \mathrm{L}$ of Leishmania tropica KWH23 log phase culture, and $10 \mu \mathrm{L}$ of each plant dilution were dispensed to different wells of microtitter plate. Here, DMSO was used as a negative control while Glucantime as positive control. Afterwards, microtitter plate was incubated at $24^{\circ} \mathrm{C}$ for $72 \mathrm{~h}$. After incubation, about $15 \mu \mathrm{L}$ of each dilution was pipetted on a neubauer counting chamber and was counted under a microscope.

2.6. Toxicity Studies. To estimate the toxicity of the plant extracts and fractions, brine shrimp lethality assay was used. For the hatching of brine-shrimps (Artemia salina) eggs, at 


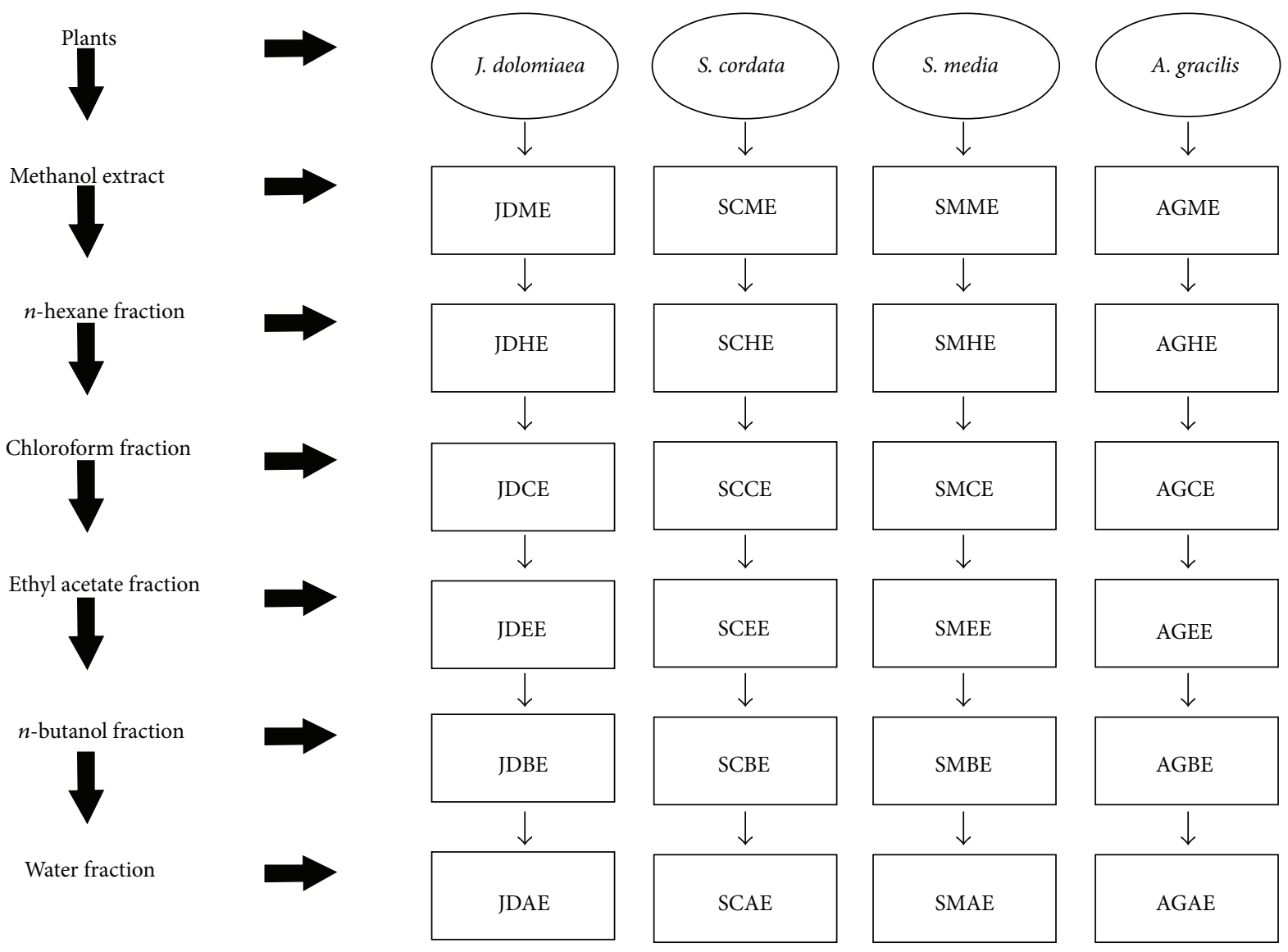

FIgURE 1: Flow sheet of extraction and fractionation of J. dolomiaea, S. cordata, S. media, and A. gracilis.

an ambient temperature of $23 \pm 1^{\circ} \mathrm{C}$ artificial sea water $(3.8 \mathrm{~g}$ sea salt/L) was used [22]. Three different concentrations of each extract $(2500,500$, and $50 \mu \mathrm{g} / \mathrm{mL})$ were made, taken from $10 \mathrm{mg} / \mathrm{mL}$ stock solution in methanol. Methanol was evaporated before transferring shrimps to the vials. After $24 \mathrm{~h}$, the hatched shrimps were shifted to the vials filled with $5 \mathrm{~mL}$ of artificial sea water (10 shrimps per vial) along with samples. The number of the shrimps that survived the sample environment was counted after $24 \mathrm{~h}$. Tricaine methanesulfonate was used as standard.

2.7. Statistical Analysis. Graph Pad Prism software version 5.0 (2007) was used to calculate $\mathrm{LC}_{50}$ and $\mathrm{IC}_{50}$ values of each sample for brine shrimp toxicity assay and antileishmanial activity. Nonlinear regression test was used to determine $R^{2}$, $\mathrm{LC}_{50}$, and $\mathrm{IC}_{50}$ values.

\section{Results}

3.1. Qualitative Phytochemistry. In qualitative phytochemical investigation, J. dolomiaea methanol extract and JDCE fraction showed the presence of all the classes of phytochemicals determined in this study except phlobatannins that was not recorded in JDCE. However, flavonoids, phenolics, alkaloids, and phlobatannins were not observed in JDHE whereas JDEE showed absence of alkaloids and tannins. In JDBE alkaloids, phlobatannins and saponins were lacking while JDAE showed the presence of only saponins, cardiac glycosides, and phenolics.

Phytochemicals appearances were altered in different fractions with a change of nature of fraction solvent. Anthraquinones and phlobatannins were absent in all fractions of $A$. gracilis as well as extract. AGHE, AGCE, and AGAE expressed the presence of only tannins, saponins, and cardiac glycosides. AGEE illustrated absence of tannins and saponins. Flavonoids, phenolics, saponins, and alkaloids were absent in AGBE.

In case of $S$. cordata, SCME, SCCE, and SCEE showed the presence of all kinds of chemical classes. Alkaloids, anthra quinones, phlobatannins, cardiac glycosides, and coumarins were not reported in the SCHE. SCBE fraction did not possess the anthraquinones, phlobatannins, and coumarins while in SCAE alkaloids, anthraquinones, phlobatannins, tannins, and coumarins were absent.

Anthraquinones and phlobatannins were absent in crude methanol extract of S. media. Alkaloids, anthraquinones, phlobatannins, and cardiac glycosides were not found in SMCE and SMEE. Only saponins, cardiac glycosides, 
flavonoids, and phenolics showed their presence. Terpenoids, saponins, cardiac glycosides, flavonoids, and phenolics were observed in SMHE and SMAE.

3.2. Antileishmanial Activity. Table 2 displays $\mathrm{IC}_{50}$ values of plants studied for antileishmanial activity. Jurinea dolomiaea JDEE fraction exhibited the best activity in terms of $\mathrm{IC}_{50}$ value $(5.3 \pm 0.2 \mu \mathrm{g} / \mathrm{mL})$ comparably low than standard drug Glucantime $(5.6 \pm 0.25)$ against Leishmania tropica promastigotes. Highest $\mathrm{IC}_{50}$ was expressed by JDCE. $\mathrm{IC}_{50}$ values of JDME, JDEE, JDHE, and JDAE fall in a range with minor differences. Regression square $\left(R^{2}\right)$ value ranged $0.81-$ 0.9 .

In case of $A$. gracilis, AGAE showed the lowest $\mathrm{IC}_{50}$ $(12.6 \pm 1.5 \mu \mathrm{g} / \mathrm{mL})$ while the highest $\mathrm{IC}_{50}$ was displayed by AGHE $(36.6 \mu \mathrm{g} / \mathrm{mL})$. AGME, AGCE, AGEE, and AGBE demonstrated $\mathrm{IC}_{50}$ values of $33.9 \pm 1.5,28.3 \pm 3.5,13.5 \pm 0.7$, and $18.9 \pm 1.2 \mu \mathrm{g} / \mathrm{mL}$, respectively. Regression square $\left(R^{2}\right)$ value ranged $0.79-0.98$.

SCHE exhibited the lowest $\mathrm{IC}_{50}(9.2 \mu \mathrm{g} / \mathrm{mL})$ in S. cordata samples while the highest by SCAE $(259.1 \pm 12.5 \mu \mathrm{g} / \mathrm{mL})$. SCEE, SCCE, SCME, and SCBE showed $\mathrm{IC}_{50}$ values of $56.8 \pm$ $5.5,125.5 \pm 4.5,41.8 \pm 2.1$, and $228.5 \pm 10.2 \mu \mathrm{g} / \mathrm{mL}$, respectively. Regression square $\left(R^{2}\right)$ value ranged $0.74-0.98$.

Methanol extract of $S$. media demonstrated $\mathrm{IC}_{50}$ value of $185.9 \pm 7.5 \mu \mathrm{g} / \mathrm{mL}$. However, SMEE displayed the lowest $\mathrm{IC}_{50}$ value of $36.4 \pm 2.5 \mu \mathrm{g} / \mathrm{mL}$ followed by SMBE, SMCE, SMHE, and SMAE. Regression square $\left(R^{2}\right)$ value ranged $0.85-0.98$.

3.3. Brine Shrimp Toxicity. Brine shrimp toxicity is an easy and economical in vitro assay to determine toxicity and safety of crude extract. Brine shrimp in vitro assay was performed to evaluate the safety assessment extracts and its derived fractions. Table 2 displays toxicity data of plants. JDME extract showed $\mathrm{LC}_{50}$ of $733.0 \pm 15.1 \mu \mathrm{g} / \mathrm{mL}$. In derived fractions, $\mathrm{LC}_{50}$ ranged from $569.5 \pm 7.4$ to $1593 \pm 20.2 \mu \mathrm{g} / \mathrm{mL}$. Lowest $\mathrm{LC}_{50}$ was shown by JDEE while higher by JDAE. Regression $R^{2}$ ranged 0.92-1.0.

AGME showed $\mathrm{LC}_{50}$ of $321.5 \pm 11.5 \mu \mathrm{g} / \mathrm{mL}$. In derived fractions, $\mathrm{LC}_{50}$ ranged from $211.9 \pm 3.7$ to $588.63 \pm 7.2 \mu \mathrm{g} / \mathrm{mL}$. The lowest $\mathrm{LC}_{50}$ was displayed by AGEE while higher $\mathrm{LC}_{50}$ value was exhibited by AGBE. Regression $R^{2}$ ranged 0.71-0.97.

SCME extract of $S$. cordata showed $\mathrm{LC}_{50}$ of $125.7 \pm$ $1.5 \mu \mathrm{g} / \mathrm{mL}$. However, $\mathrm{LC}_{50}$ value of its derived fractions expressed higher values and ranged from $211.9 \pm 2.9$ to $882.4 \pm$ $6.3 \mu \mathrm{g} / \mathrm{mL}$. The lowest $\mathrm{LC}_{50}$ was shown by SCAE while the highest by SCBE. Regression square ranged 0.75-0.99.

In case of $S$. media, SMME extract showed $\mathrm{LC}_{50}$ value of $436.7 \mu \mathrm{g} / \mathrm{mL}$ whereas its derived fractions exhibited comparatively higher $\mathrm{LC}_{50}$ values and ranged from $660.7 \pm 2.5$ to $789.3 \pm 2.7 \mu \mathrm{g} / \mathrm{mL}$. The lowest $\mathrm{LC}_{50}$ was shown by SMAE while the highest by SMEE. Regression square ranged 0.85-0.99.

\section{Discussion}

Phytochemical screening is the first step in herbal medicine research to identify bioactive and novel lead compounds. Plant material consists of many different kinds of natural products with nature of different polarities leading to a different mode of solubility [23, 24].

In the present study, extraction with crude methanol was obtained by soaking for 4-5 days with frequent shaking in the ratio of $1 \mathrm{~kg}$ powder : 2 liter of crude methanol. Sequential fractionation with escalating polarity of solvent, $n$-hexane, chloroform, ethyl acetate, and $n$-butanol was followed in this experiment. In the end, residue portion was termed as aqueous fraction.

In qualitative analysis, crude methanol extract illustrated maximum number of different classes of compounds for all the plants under present study. Similar observations were reported by Saeed et al. [25] and Rashid et al. [26] in their studies on Torilis leptophylla and Fagonia olivieri, respectively. Preliminary qualitative screening which ascertains these plants may have potential bioactive components. The present study reports that J. dolomiaea, A. gracilis, and $S$. cordata are potential source of bioactive compounds in term of flavonoids, phlobatannins, phenolics, alkaloids, anthraquinones, saponins, coumarins, tannins, terpenoids, and cardiac glycosides. Stellaria media also showed all classes except anthraquinones and phlobatannins. The presence of such bioactive components explains the use of these plants in the folk medicine.

Leishmaniasis is nowadays an important parasitic problem in the world. There is a need to identify new drugs against the parasite causing leishmaniasis. Antileishmanial activity was performed to expose potential in inhibiting and retarding multiplication of leishmanial parasite.

Different fractions of methanol extract of the plants used in this study indicated that JDEE of J. dolomiaea, SMEE of $S$. media exhibited the lowest $\mathrm{IC}_{50}$ among the different fractions. This activity may be due to the high content of flavonoids and phenolics. García et al. [27] have reported the flavanols constituents of Pluchea carolinensis as antileishmanial agents. Some other studies showed the presence of phytochemicals possessing antileishmanial activity such as flavones [28] and alkaloids [29]. Kolodziej et al. [30] verified polyphenols for their antiparasitic activity. Marín et al. [31] analyzed couple of flavonoids from Consolida oliveriana. Antileishmanial activity versus promastigote and amastigote type documented pertaining to kaempferol, quercetin, and trifolin along with their O-acetyl derivatives and acetyl hyperoside as well as octa-O-acetyl hyperoside. These compounds were observed to be noncytotoxic and with efficacy equal or lower than the reference drugs, that is, Pentostam and Glucantime. SCHE presented the lowest $\mathrm{IC}_{50}$ among $S$. cordata and AGAE for A. gracilis, proposing some other bioactive phytochemical other than flavonoids and phenolics. Thus, there is a need of further study to investigate the active compounds responsible for antileishmanial activity and its in vivo application to sought out its appropriate concentration against Leishmania in infected experimental organisms. It would be helpful in designing new medicines which are biologically more active and cost-effective and having minimum side effects.

Most of the pharmacologically active compounds are obtained from the natural sources. Because of the traditional use, most of them are safely utilized nowadays. But when we move towards new discoveries from the medicinal 
TABLE 2: Antileishmanial and toxicity activity of J. dolomiaea, A. gracilis, S. cordata, and S. media methanol extract and its derived fractions.

\begin{tabular}{|c|c|c|c|c|}
\hline \multirow{2}{*}{ Sample } & \multicolumn{2}{|c|}{ Antileishmanial } & \multicolumn{2}{|c|}{ Toxicity } \\
\hline & $R^{2}$ & $\mathrm{IC}_{50}(\mu \mathrm{g} / \mathrm{mL})$ & $R^{2}$ & $\mathrm{LC}_{50}(\mu \mathrm{g} / \mathrm{mL})$ \\
\hline \multicolumn{5}{|l|}{ J. dolomiaea } \\
\hline JDME & 0.84 & $10.9 \pm 1.1$ & 1.00 & $733.0 \pm 15.1$ \\
\hline JDHE & 0.95 & $7.2 \pm 0.5$ & 0.98 & $982.5 \pm 12.3$ \\
\hline JDCE & 0.81 & $47.7 \pm 2.3$ & 0.98 & $834.5 \pm 8.5$ \\
\hline JDEE & 0.98 & $5.3 \pm 0.2$ & 0.98 & $569.5 \pm 7.4$ \\
\hline JDBE & 0.97 & $21.8 \pm 2.4$ & 0.95 & $958.3 \pm 10.8$ \\
\hline JDAE & 0.97 & $6.0 \pm 0.1$ & 0.92 & $1593 \pm 20.2$ \\
\hline \multicolumn{5}{|l|}{ A. gracilis } \\
\hline AGME & 0.82 & $33.9 \pm 1.5$ & 0.71 & $321.5 \pm 11.5$ \\
\hline AGHE & 0.79 & $36.6 \pm 1.4$ & 0.97 & $280.6 \pm 4.3$ \\
\hline AGCE & 0.94 & $28.3 \pm 3.5$ & 0.86 & $383.5 \pm 9.5$ \\
\hline AGEE & 0.92 & $13.5 \pm 0.7$ & 0.94 & $211.9 \pm 3.7$ \\
\hline AGBE & 0.95 & $18.9 \pm 1.2$ & 0.84 & $588.6 \pm 7.2$ \\
\hline AGAE & 0.98 & $12.6 \pm 1.5$ & 0.89 & $460 \pm 12.5$ \\
\hline \multicolumn{5}{|l|}{ S. cordata } \\
\hline SCME & 0.90 & $41.8 \pm 2.1$ & 0.99 & $125.7 \pm 1.5$ \\
\hline SCHE & 0.90 & $9.2 \pm 0.7$ & 0.75 & $879.5 \pm 1.3$ \\
\hline SCCE & 0.89 & $125.5 \pm 4.5$ & 0.84 & $802.8 \pm 4.7$ \\
\hline SCEE & 0.74 & $56.8 \pm 5.5$ & 0.94 & $309.9 \pm 3.3$ \\
\hline SCBE & 0.98 & $228.5 \pm 10.2$ & 0.92 & $882.4 \pm 6.3$ \\
\hline SCAE & 0.92 & $259.1 \pm 12.5$ & 0.94 & $211.9 \pm 2.9$ \\
\hline \multicolumn{5}{|l|}{ S. media } \\
\hline SMME & 0.95 & $185.9 \pm 7.5$ & 0.99 & $436.7 \pm 8.2$ \\
\hline SMHE & 0.99 & $170.4 \pm 5.5$ & 0.88 & $542.5 \pm 10.4$ \\
\hline SMCE & 0.83 & $155.5 \pm 3.8$ & 0.98 & $600.0 \pm 6.5$ \\
\hline SMEE & 0.85 & $36.4 \pm 2.5$ & 0.85 & $789.3 \pm 2.7$ \\
\hline SMBE & 0.93 & $49.5 \pm 3.5$ & 0.95 & $760.2 \pm 13.6$ \\
\hline SMAE & 0.98 & $184.8 \pm 5.8$ & 0.96 & $660.7 \pm 2.5$ \\
\hline Glucantime & 0.99 & $5.6 \pm 0.25$ & - & - \\
\hline Tricaine methanesulfonate & - & - & 0.93 & $4.3 \pm 0.15$ \\
\hline
\end{tabular}

-: represents activity not performed.

plants, the toxicity profile of the respective plant must also be checked in order to enhance safety [32]. Pharmacological evaluation of plants provides a good source for the development of novel and safe medicinal plants. The brine shrimp toxicity is considered an inexpensive, rapid, convenient, and reliable assay for determination of toxicity of a pure compound or medicinal plant extracts or fractions [33]. In the present study, all the plant extracts and their derived fractions showed $\mathrm{LC}_{50}$ values in safety range following the statement of Peteros and Uy [34], placing crude extract in nontoxic having $\mathrm{LC}_{50}>100 \mu \mathrm{g} / \mathrm{mL}$ for brine shrimp.

Krishnaraju et al. [35] investigated 120 plants aqueous extract toxicity by using brine shrimp lethality study. Pistacia lentiscus showed lower $\mathrm{LC}_{50}$ of $2.5 \mu \mathrm{g} / \mathrm{mL}$. Boswellia serrata, Aristolochia indica, Garcinia cambogia, Ginkgo biloba, and Semecarpus anacardium showed significant toxicity with $\mathrm{LC}_{50}$ of $18,13,22,21$, and $29.5 \mu \mathrm{g} / \mathrm{mL}$, respectively. Additionally, Krishnaraju et al. [36] reported brine shrimp toxicity of aqueous extracts of 118 Indian medicinal plants and discovered eleven out of the 118 extracts with critical harmfulness to the brine shrimp $\left(\mathrm{LC}_{50}<60 \mu \mathrm{g} / \mathrm{mL}\right)$. Polygonum cuspidatum and Syzygium cumini extracts have shown strong action with $\mathrm{LC}_{50}$ of 13.5 and $20 \mu \mathrm{g} / \mathrm{mL}$, respectively.

In the present study, brine shrimp toxicity study also supports the acute toxicity study where fractions used for the in vivo studies in animal models were found safe with high doses.

\section{Conclusion}

The results depict that the plants described above have highly potent compounds involving in antileishmanial activity and they can be used as an effective mean against Leishmania. Therefore, further studies are required for the isolation of these effective compounds and in vivo implementation. 


\section{Conflict of Interests}

The authors declare no conflict of interests.

\section{References}

[1] F. Oliveira, R. C. Jochim, J. G. Valenzuela, and S. Kamhawi, "Sand flies, Leishmania, and transcriptome-borne solutions," Parasitology International, vol. 58, no. 1, pp. 1-5, 2009.

[2] A. M. Bhutto, F. R. Soomro, and K. Katakura, "Leishmaniasis in Sindh, Pakistan: outbreak and review of the literature," Journal of Pakistan Association of Dermatologists, vol. 18, no. 4, pp. 212219, 2008.

[3] S. J. Khan and S. Muneeb, "Cutaneous leishmaniasis in Pakistan," Dermatology Online Journal, vol. 11, no. 1, article 4, 2005.

[4] J. Soto, B. A. Arana, J. Tolado et al., "Miltefosine for new world cutaneous leishmaniasis," Clinical Infectious Diseases, vol. 38, no. 9, pp. 1266-1272, 2004.

[5] D. S. Corrêa, A. G. Tempone, J. Q. Reimão et al., "Antileishmanial and anti-trypanosomal potential of polygodial isolated from stem barks of Drimys brasiliensis Miers (Winteraceae)," Parasitology Research, vol. 109, no. 1, pp. 231-236, 2011.

[6] N. C. Hepburn, M. J. Tidman, and J. A. A. Hunter, "Aminosidine (paromomycin) versus sodium stibogluconate for the treatment of American cutaneous leishmaniasis," Transactions of the Royal Society of Tropical Medicine and Hygiene, vol. 88, no. 6, pp. 700703, 1994.

[7] J. D. Berman, R. Badaro, C. P. Thakur et al., "Efficacy and safety of liposomal amphotericin B (AmBisome) for visceral leishmaniasis in endemic developing countries," Bulletin of the World Health Organization, vol. 76, no. 1, pp. 25-32, 1998.

[8] D. O. Santos, C. E. R. Coutinho, M. F. Madeira et al., "Leishmaniasis treatment-a challenge that remains: a review," Parasitology Research, vol. 103, no. 1, pp. 1-10, 2008.

[9] P. Desjeux, "Leishmaniasis: current situation and new perspectives," Comparative Immunology, Microbiology and Infectious Diseases, vol. 27, no. 5, pp. 305-318, 2004.

[10] J. Alvar, S. Yactayo, and C. Bern, "Leishmaniasis and poverty," Trends in Parasitology, vol. 22, no. 12, pp. 552-557, 2006.

[11] R. A. Neal and S. L. Croft, "An in-vitro system for determining the activity of compounds against the intracellular amastigote form of Leishmania donovani," Journal of Antimicrobial Chemotherapy, vol. 14, no. 5, pp. 463-475, 1984.

[12] S. L. Croft, S. Sundar, and A. H. Fairlamb, "Drug resistance in leishmaniasis," Clinical Microbiology Reviews, vol. 19, no. 1, pp. 111-126, 2006.

[13] M. J. Chan-Bacab and L. M. Peña-Rodríguez, "Plant natural products with leishmanicidal activity," Natural Product Reports, vol. 18, no. 6, pp. 674-688, 2001.

[14] O. Kayser and A. F. Kiderlen, "In vitro leishmanicidal activity of naturally occurring chalcones," Phytotherapy Research, vol. 15, no. 2, pp. 148-152, 2001.

[15] O. Kayser, C. Olbrich, V. Yardley, A. F. Kiderlen, and S. L. Croft, "Formulation of amphotericin B as nanosuspension for oral administration," International Journal of Pharmaceutics, vol. 254, no. 1, pp. 73-75, 2003.

[16] A. E. Tahir, A. M. Ibrahim, G. M. Satti, T. G. Theander, A. Kharazmi, and S. A. Khalid, "The potential antileishmanial activity of some sudanese medicinal plants," Phytotherapy Research, vol. 12, no. 8, pp. 576-579, 1998.
[17] B. Weniger, S. Robledo, G. J. Arango et al., "Antiprotozoal activities of Colombian plants," Journal of Ethnopharmacology, vol. 78, no. 2-3, pp. 193-200, 2001.

[18] P. B. de Carvalho and E. I. Ferreira, "Leishmaniasis phytotherapy. Nature's leadership against an ancient disease," Fitoterapia, vol. 72, no. 6, pp. 599-618, 2001.

[19] J. Harborne, Phytochemical Methods: A Guide to Modern Techniques of Plant Analysis, Chapman and Hall, London, UK, 1998.

[20] W. C. Evans, Trease and Evans' Pharmacognosy, Elsevier Health Sciences, Philadelphia, Pa, USA, 2009.

[21] A. Sofowora, Medicinal Plants and Traditional Medicine in Africa, John Wiley \& Sons, New York, NY, USA, 1982.

[22] M. Sirajuddin, S. Ali, N. A. Shah, M. R. Khan, and M. N. Tahir, "Synthesis, characterization, biological screenings and interaction with calf thymus DNA of a novel azomethine 3-((3,5dimethylphenylimino)methyl)benzene-1,2-diol," Spectrochimica Acta A: Molecular and Biomolecular Spectroscopy, vol. 94, pp. 134-142, 2012.

[23] D. A. Starmans and H. H. Nijhuis, "Extraction of secondary metabolites from plant material: a review," Trends in Food Science \& Technology, vol. 7, no. 6, pp. 191-197, 1996.

[24] W. Jones and A. Kinghorn, "Extraction of plant secondary metabolites," in Natural Products Isolation, S. D. Sarker, Z. Latif, and A. I. Gray, Eds., Humana Press, Totowa, NJ, USA, 2006.

[25] N. Saeed, M. R. Khan, and M. Shabbir, "Antioxidant activity, total phenolic and total flavonoid contents of whole plant extracts Torilis leptophylla L," BMC Complementary and Alternative Medicine, vol. 12, article 221, 2012.

[26] U. Rashid, M. R. Khan, S. Jan, J. Bokhari, and N. A. Shah, "Assessment of phytochemicals, antimicrobial and cytotoxic activities of extract and fractions from Fagonia olivieri (Zygophyllaceae)," BMC Complementary and Alternative Medicine, vol. 13, article 167, 2013.

[27] M. García, W. H. Perera, R. Scull, and L. Monzote, "Antileishmanial assessment of leaf extracts from Pluchea carolinensis, Pluchea odorata and Pluchea rosea," Asian Pacific Journal of Tropical Medicine, vol. 4, no. 10, pp. 836-840, 2011.

[28] S. S. Grecco, J. Q. Reimão, A. G. Tempone et al., "Isolation of an antileishmanial and antitrypanosomal flavanone from the leaves of Baccharis retusa DC. (Asteraceae)," Parasitology Research, vol. 106, no. 5, pp. 1245-1248, 2010.

[29] A. González-Coloma, M. Reina, C. Sáenz et al., "Antileishmanial, antitrypanosomal, and cytotoxic screening of ethnopharmacologically selected Peruvian plants," Parasitology Research, vol. 110, no. 4, pp. 1381-1392, 2012.

[30] H. Kolodziej, O. Kayser, A. Kiderlen et al., "Antileishmanial activity of hydrolyzable tannins and their modulatory effects on nitric oxide and tumour necrosis factor- $\alpha$ release in macrophages in vitro," Planta Medica, vol. 67, no. 9, pp. 825-832, 2001.

[31] C. Marín, S. Boutaleb-Charki, J. G. Díaz et al., "Antileishmaniasis activity of flavonoids from Consolida oliveriana," Journal of Natural Products, vol. 72, no. 6, pp. 1069-1074, 2009.

[32] D. Olila, J. Opuda-Asibo, and Olwa-Odyek, "Bioassay-guided studies on the cytotoxic and in vitro trypanocidal activities of a sesquiterpene (Muzigadial) derived from a Ugandan medicinal plant (Warburgia ugandensis)," African Health Sciences, vol. 1, no. 1, pp. 12-15, 2001.

[33] B. N. Meyer, N. R. Ferrigni, J. E. Putnam, L. Jacobsen, D. Nichols, and J. McLaughlin, "Brine shrimp: a convenient general bioassay for active plant constituents," Planta Medica, vol. 45 , no. 5, pp. 31-34, 1982. 
[34] N. P. Peteros and M. M. Uy, "Antioxidant and cytotoxic activities and phytochemical screening of four Philippine medicinal plants," Journal of Medicinal Plant Research, vol. 4, no. 5, pp. 407-414, 2010.

[35] A. V. Krishnaraju, T. V. Rao, D. Sundararaju, M. Vanisree, H.-S. Tsay, and G. V. Subbaraju, "Assessment of bioactivity of Indian medicinal plants using Brine shrimp (Artemia salina) lethality assay," International Journal of Applied Science and Engineering, vol. 3, no. 2, pp. 125-134, 2005.

[36] A. V. Krishnaraju, T. V. Rao, D. Sundararaju, M. Vanisree, H.-S. Tsay, and G. V. Subbaraju, "Biological screening of medicinal plants collected from Eastern Ghats of India using Artemia salina (Brine shrimp test)," International Journal of Applied Science and Engineering, vol. 4, no. 2, pp. 115-125, 2006. 

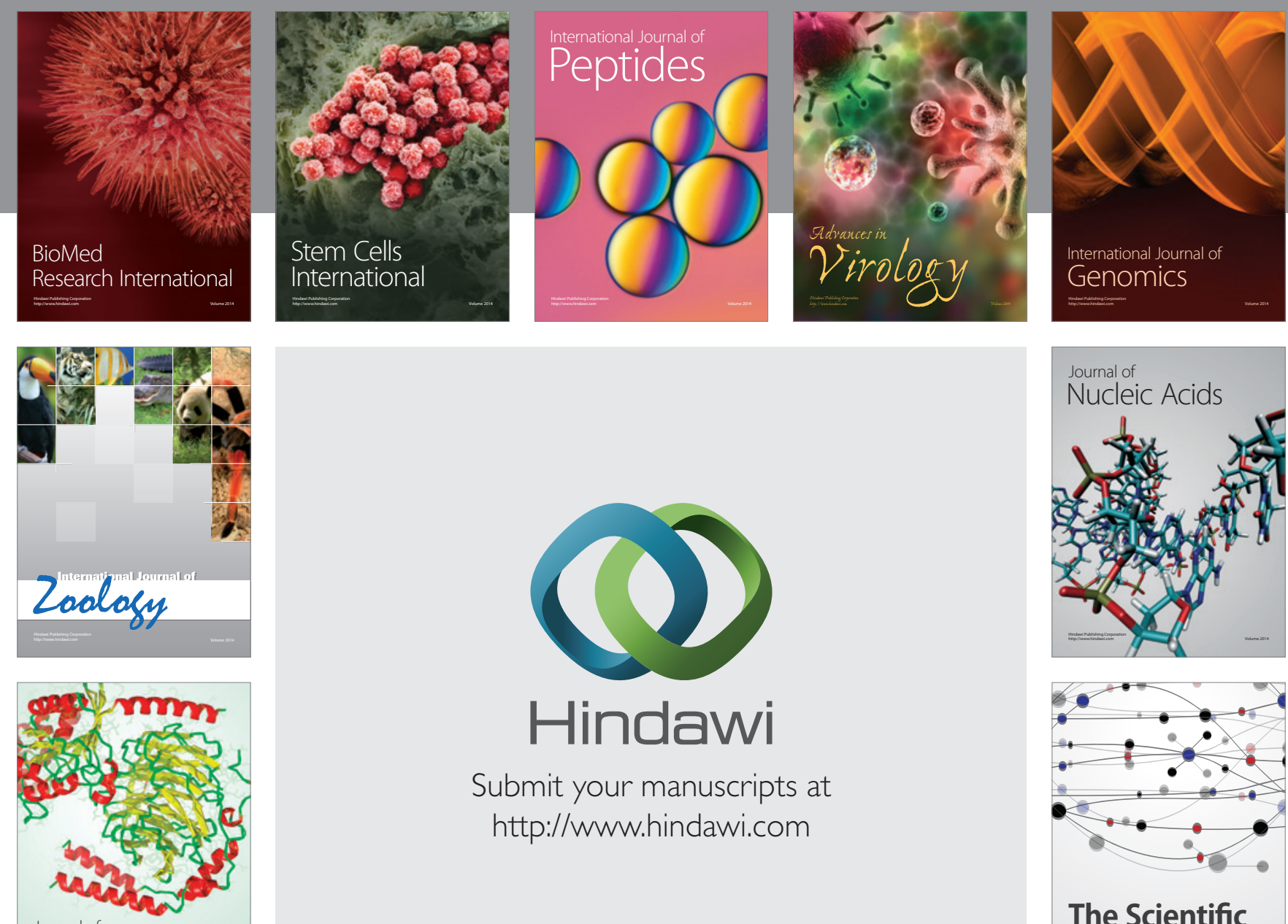

Submit your manuscripts at

http://www.hindawi.com

Journal of
Signal Transduction
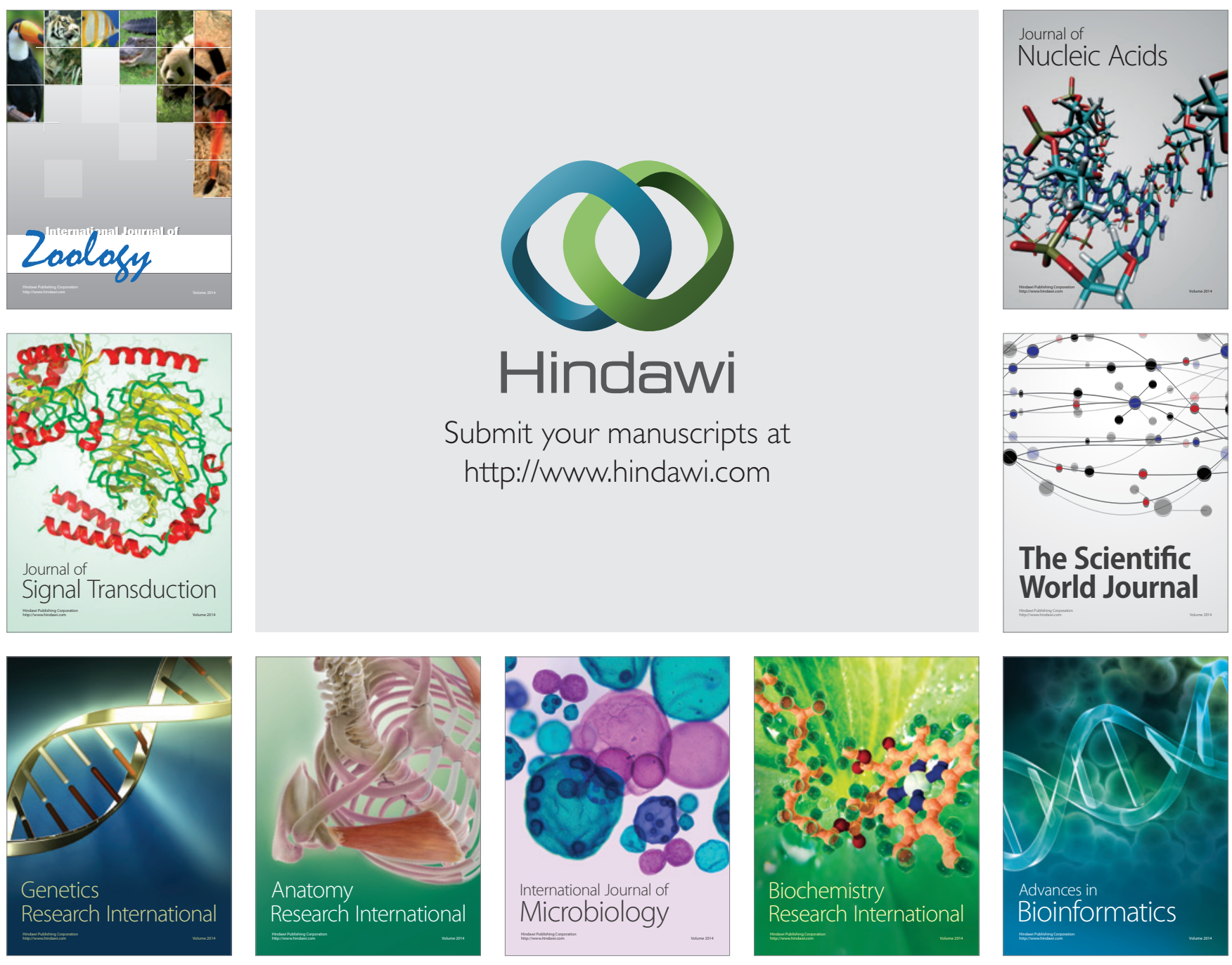

The Scientific World Journal
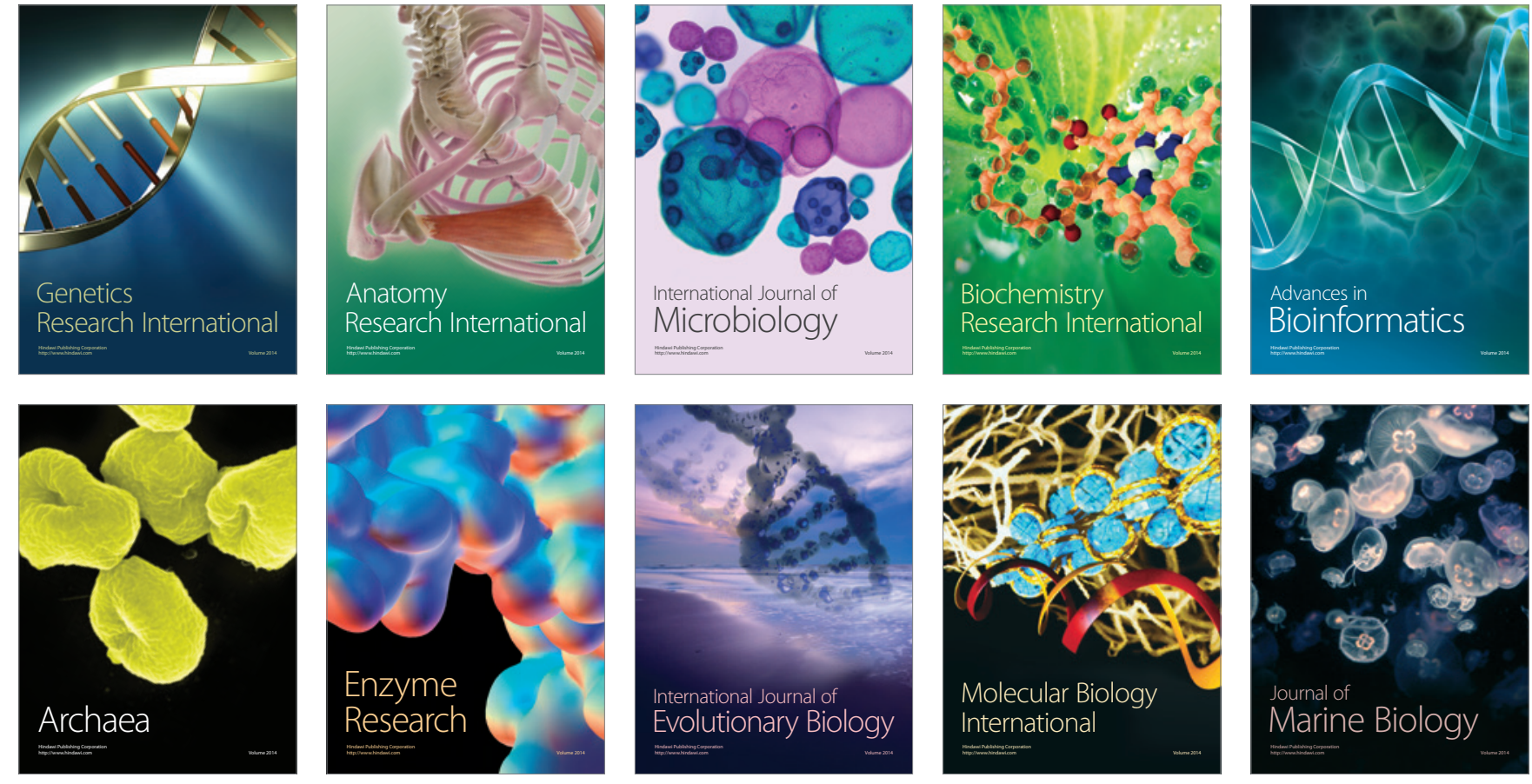